\title{
Factors influencing the environmental and economic feasibility of district heating systems-a perspective from integrated spatial and energy planning
}

\author{
Franz Zach ${ }^{1}$, Susanna Erker ${ }^{2^{*}}$ (D) and Gernot Stoeglehner ${ }^{2}$
}

\begin{abstract}
Background: District heating systems have been gaining importance in the last years. However, local circumstances, e.g. regarding heat demand and available heat sources, are diverse and new technologies especially in the low-temperature sector arise. Central aim of this research is to identify the impact of integrated spatial and energy planning on the environmental and economic sustainability of district heating systems, to distinguish between more and less appropriate areas for district heating and to build the basis for a low-barrier decision tool for local authorities regarding the identification of areas suitable for district heating, also showing spatial planning strategies to enhance the opportunities for district heating. Future changes until 2050 are analysed and planning principles derived; therefore, unpredictable parameters such as energy prices and subsidies are not included in this research.
\end{abstract}

Methods: Based on the system analysis according to Vester, a modified method was developed. The following research fields were involved: spatial planning, resource management, environmental planning, and energy and building technology.

Results: As main integrated spatial and energy planning aspects relevant for district heating, mix of functions, potential of compacting and extension, density of buildings, inhabitants and employees, building type, thermal insulation potential, and the used heat source(s) were identified. By steering these parameters, the feasibility of district heating systems can be enhanced. Indicators, directly linked to the feasibility of district heating systems are energy consumption density, number of annual full load hours, temperature level, and available heat source(s). Climate change, changes in building density, thermal insulation, and the mix of functions will influence district heating systems regarding environmental and economic aspects. Reduced heat consumption can be a threat to district heating systems, but can be balanced by decreasing inlet temperatures, making waste heat and renewables accessible.

Conclusions: As district heating systems are often advantageous to other forms of providing heat due to higher resilience, the economies of scale effect, or the potential of using energy surpluses ('waste heat'), spatial planning policies must seek ways to provide for adequate building density and to enhance the mix of functions in order to ensure the long-term feasibility of district heating systems.

Keywords: Heat demand, Environmental feasibility, Economic feasibility, Heating, Vester, District heating, Heat grid, Spatial planning, System analysis

\footnotetext{
* Correspondence: susanna.erker@boku.ac.at

${ }^{2}$ Institute of Spatial Planning, Environmental Planning and Land

Rearrangement, University of Natural Resources and Life Sciences, Vienna,

Peter-Jordan-Strasse 82, 1190 Vienna, Austria

Full list of author information is available at the end of the article
}

(c) The Author(s). 2019 Open Access This article is distributed under the terms of the Creative Commons Attribution 4.0 International License (http://creativecommons.org/licenses/by/4.0/), which permits unrestricted use, distribution, and reproduction in any medium, provided you give appropriate credit to the original author(s) and the source, provide a link to the Creative Commons license, and indicate if changes were made. 


\section{Background}

District heating is a grid-based technology of delivering heating energy by distributing warm water (rarely steam) used for different demands such as process heating, room heating, warm water, or even cooling. District heating systems (DHS) can rely on multiple energy sources. In comparison to other forms of heating (e.g. gas or biomass heating), DHS are more complex and variant due to the fact that the energy source mix in DHS with multiple heat sources (like gas CHP (combined heat and power) plants, waste incineration, industrial waste heat, biomass) can change on annual and even daily basis. Therefore, the environmental and economic feasibility of DHS addresses both energy source mix and load profiles, contrary to other heating systems. Despite this high degree of complexity and dynamic, DHS are of increasing importance. In Austria, for example, the final energy distributed through DHS increased from $54,333 \mathrm{TJ}$ in 2005 to $72,718 \mathrm{TJ}$ in 2016 , accounting for $6.5 \%$ of the total energy consumption in 2016 [1], representing a share of $21 \%$ in the space heating market. On a worldwide scale, the market share is very diverse: $58 \%$ in Denmark, $48 \%$ in Finland, $12 \%$ in Germany, and $1.2 \%$ in Japan [2]. In total, 80,000 district heating systems exist, 6000 of them in Europe [3].

Considering already established systems, most DHS are designed for delivering heat only. However, there also exist grids covering heating as well as cooling purposes. They are called 'ambient DHS' or 'low temperature DHS' ${ }^{1}$ and distribute heat at temperatures between 10 and $20^{\circ} \mathrm{C}$. Such grids include decentralized heat pumps delivering the particularly needed temperature, whereas standard technology grids distribute heat at directly usable temperature level. If at least $1 \mathrm{kWh}$ of cooling energy per $5.7 \mathrm{kWh}$ of heating energy is needed, a common grid for heating and cooling purposes is preferable [4]. In the future, cooling will gain importance due to climate change. Therefore, such combined systems are likely to become more popular.

Realization of low-temperature district heating can positively influence the usability of renewables and waste heat [5]. In this respect, the Suurstoffi quarter in Switzerland shall be mentioned, representing an example for ambient DHS. Within the quarter, residential, industrial, and commercial buildings are mixed, while the energy supply system depends on renewable energy only. The DHS at hand consists of two pipes, where the inlet flow pipe for heating is the return flow pipe for cooling and vice versa. Waste heat from cooling or industrial processes can be either used directly for heating another 'prosumer' (producing cooling energy means consuming heating energy and vice versa) or put into a seasonal geothermal storage. PVT collectors (photovoltaic thermal resp. hybrid solar collectors) deliver electricity for the heat pumps as well as heat for recovering the seasonal storage [6]. By using non-fossil technologies in DHS, the independence of volatile fuel prices can be reached. However, sources are often lowtemperature and small-scale; therefore, the grids have to be adapted (cascading, storing, etc.) as well as buildings (floor heating). Also, the low availability of sources during wintertime makes storages necessary; on the other hand, absorption chillers can use surpluses in summer for cooling [7]. District cooling is a comparably small market (150 European systems [3]) but is not only limited to a warmer climate. Even for a quarter in Malmö, Sweden, the annual cooling energy consumption exceeds the annual heat energy consumption [8]. Quarters where annual heating and cooling demands are approximately balanced are ideal for combined heating and cooling grids.

Another trend can be linked to the usability of currently rather unnoticed energy sources such as wastewater ([9-12]) which has a remarkable potential for ambient DHS. An international example represents Tokyo, where $180 \mathrm{MW}$ can be produced from sewage resp. $250 \mathrm{MW}$ from wastewater treatment plants. The energy potential in Austria resulting from effluent wastewater is estimated at 3.1 TWh/a. Other sources usable for ambient DHS are groundwater, soil, waste heat from cooling, solar thermal energy, and outside air [13] consider wastewater as the most favourable heat source for heat pumps among seven investigated ambient and waste heat sources for heat pumps regarding temperature, stability/security, and proximity to urban areas.

Despite these positive cases of application, the question of advantages and disadvantages of district heating and/or district cooling systems compared to other energy supply technologies must be answered case by case. According to a literature research, the following advantages can be stated:

(i) DHS are flexible regarding a change of energy sources. Due to the mix of heterogeneous energy sources, DHS can be seen as a resilient technology $([14,15])$. Local heating generation systems (per house or flat) rely on only one energy source, e.g. natural gas. If its delivery is blocked for whatever reason (most European countries are net importers of fossil fuels), local boilers cannot work. In DHS with multiple energy sources, modifications in the heat production mix can be managed to a certain extent without implementing new production sites in case of lack or price change of one energy source [11]. Adapting the energy source mix in a DHS is associated with less effort than changing the boilers in thousands of households (e.g. 391,733 households are attached to the DHS in Vienna [16]).

(ii) Apart from the opportunity of using different heat sources to optimize environmental and economic parameters, DHS profit from the 'economies of 
scale effect', commonly known in microeconomics; large enterprises obtain cost advantages due to a larger scale of operation. Even large DHS such as the Korean District Heating Corporation, selling 13 TWh of heat in 2013, could become more costeffective by extension of their heating grid [17]. This effect also affects exhaust gas cleaning devices for all combustion plants; more effective cleaning technologies can be implemented in DHS than in local boilers. Accordingly, the market share of district heating is higher in larger cities; however, this is also due to a higher heat demand density [18].

(iii) DHS can have positive effects on the economic feasibility of renewable electric power plants. Using electricity in DHS via electric boilers or-more efficiently-via heat pumps may stabilize electricity prices, leading to higher prices for volatile renewable energies. This may reduce the need of subsidies for renewable electricity technologies [19].

(iv) No individual boilers are needed which reduces investment and maintenance costs as well as needed space within households. Moreover, in many cases, lower consumer energy prices as well as higher market prices of houses compared to houses with other forms of heat supply occur [17].

Besides, various disadvantages or limitations of DHS have to be mentioned:

(i) Constructing grid infrastructure needs resources like insulation material and metal as well as energy. The more heat can be delivered in a certain grid (higher heat consumption density: minimum values vary between $50 \mathrm{kWh} / \mathrm{m}^{2} \mathrm{a}$ [20] and $120 \mathrm{kWh} / \mathrm{m}^{2} \mathrm{a}$ [2]), the less this effect will be relevant. Especially, spatial planning parameters have a large impact on DHS [21].

(ii) Heat losses within the grid reduce the overall system efficiency. Again, this effect has to be related to the delivered heat.

(iii) In conventional DHS, the grid temperature has to be adjusted to the consumer that needs the highest temperature within one grid [22]. Subsequently, many systems run on temperatures above $100{ }^{\circ} \mathrm{C}$ although most attached consumers would only need lower temperatures. This excludes the utilization of many waste and renewable heat sources while fossil sources are not affected. Grids with decentralized heat pumps can surpass this effect, however, representing the minority in the DHS stock.

In addition to these general advantages and disadvantages, current development processes influence the long-term feasibility of DHS. Therefore, several challenges regarding DHS can be enumerated: (a) Climate change [23] affects DHS by increased outside temperatures, leading to a reduced heat energy consumption density; therefore, investments into grids will become less cost-effective.

(b) Thermal insulation reduces the heat consumption density and therefore also the economic feasibility [18], but may enhance the feasibility of DHS by reducing the needed temperature levels. This would have positive effects on the feasibility of heat pump solutions and may decrease heat losses.

(c) The functions of supplied buildings have a remarkable influence on their consumption profiles [24]. Well-mixed quarters have a higher number of annual full load hours [11], leading to a better economic feasibility for DHS. An energy surplus (waste heat) can be transferred to other heat consumers via DHS. Without DHS, waste heat can only be stored or cannot be used at all. Using local energy surpluses is also advantageous to reach regional energy autonomy which strengthens the local economy, creates workplaces, and decreases dependency on fossil fuel imports from politically instable regions. This means the future challenge will be to design well-mixed urban quarters.

(d) Passive houses and building stock refurbishments reduce the specific thermal energy consumption and subsequently reduce the heat consumption density. Therefore, in newly built or refurbished areas, DHS face new challenges regarding their environmental and economic feasibility as higher heat consumption densities are beneficial. However, process heat and heat for domestic hot water production are not affected by enhanced building insulation.

(e) The priorisation of energy sources can influence the economically optimal DHS configuration [25]-e.g. the dimensioning of heat storages has different economic optima depending on the priorisation of energy sources. This means that changing price relations between different energy sources may impair the economic feasibility of a DHS.

Analysing the abovementioned advantages, disadvantages, and challenges, the following main questions may arise referring to the long-term feasibility of DHS:

(R1) Which are the main drivers that determine the economic and environmental feasibility of DHS?

(R2) How can these drivers be influenced in a positive way and what are the main indicators showing this positive influence?

(R3) How will future development processes influence these drivers and therefore the long-term feasibility of DHS?

(R4) Which planning principles and recommendations can be derived from these findings? 
To answer these questions, this article addresses the system interrelations between spatial structures as well as environmental, technical, and economic issues of DHS. Factors which are unpredictable and volatile, especially concerning the 2050 perspective, such as energy prices, subsidies and taxes, are excluded. However, the comparison between prices for district heating and local heat generation depending on the spatial framework conditions is the main focus of this research as the installation costs depending on the spatial structure are analysed and heat sources in district heating systems are diverse and flexible (and often the same as in local boilers). Consequently, possible developments influencing the feasibility of DHS until 2050 are discussed. In order to perform a fundamental analysis of the system 'district heating', experts from different research fields gave insights on DHS, resulting in an interdisciplinary research approach. Derived from the variety of expert views, a coordinated set of planning principles will be introduced upon this research, which can enhance the environmental and economic feasibility of DHS in the future.

\section{Materials and methods}

The complexity of the system 'district heating' necessitates specific methods to understand the interaction between influencing parameters and to predict the future of DHS under given changes. Therefore, a four-step methodological framework was developed (see Fig. 1).

The identification of parameters (first two lines in Fig. 1) builds the fundament of further analysis as it defines the parameters taken into account in the further research on the economic and environmental feasibility of DHS. Therefore, a comprehensive literature research as well as discussion rounds with experts from all relevant research fields is performed: spatial planning, environmental planning, energy technology, buildings technology, and resource management (see Table 1). The derived parameters are arranged in two main groups: DHS technical parameters and spatial planning parameters. All parameters have a connection to either environmental (energy consumption, emissions, resource demand) or economic or both aspects.

However, a list of parameters does not help to analyse the influence dynamics within DHS. Therefore, a system analysis after F. Vester was performed. Here, the influence of each parameter on each other parameter is evaluated (see the 'Identification of pairwise interactions between system parameters' section). Parameters which influence a lot of other parameters are of special interest as they act as '(influencing) system drivers'. They influence district heating systems (DHS) via the 'influenceable) indicators' which describe the changes of the DHS in a representative way and can be found among the remaining parameters. Moreover, some parameters will neither be system drivers nor be suitable indicators.

Hereinafter, future developments of the system drivers are investigated as they influence the future economic and environmental feasibility of DHS (see the 'Scenarios for DHS until 2050' section). A quantitative analysis of the influence of the system drivers on the indicators is done wherever possible, or else a qualitative discussion is performed.

Finally, the obtained results are reflected and their relevance for future DHS projects is analysed. This is

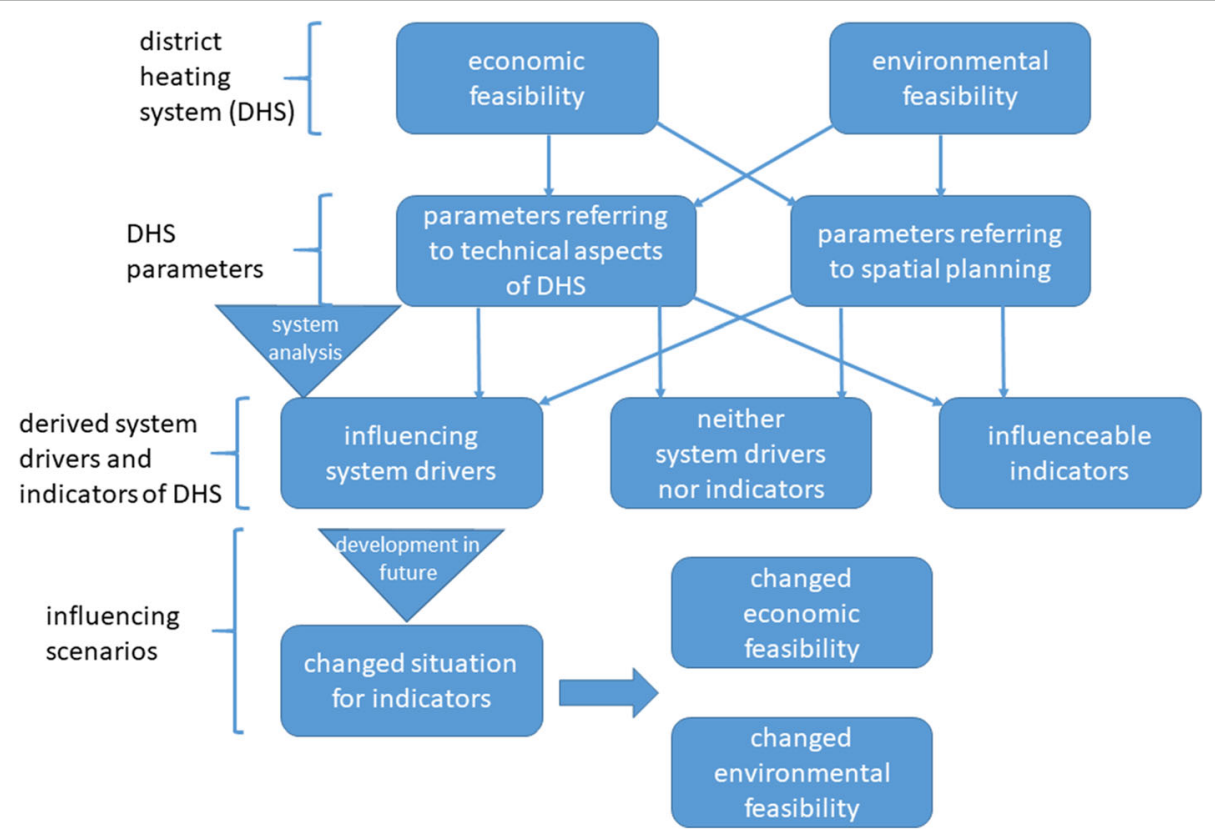

Fig. 1 Classification of the identified system parameters and connection to the scenarios (own illustration) 
Table 1 Research fields included in the system analysis on DHS and corresponding institutions (own illustration)

\begin{tabular}{|c|c|c|}
\hline Discipline & Motivation for inclusion & Institution \\
\hline $\begin{array}{l}\text { Spatial } \\
\text { planning }\end{array}$ & $\begin{array}{l}\text { Spatial aspects are important for determining the environmental } \\
\text { and economic feasibility of DHS. Therefore, aspects of spatial } \\
\text { planning are included into the system analysis of DHS. }\end{array}$ & $\begin{array}{l}\text { BOKU-IRUB: University of Natural Resources and Life Sciences, } \\
\text { Vienna, Institute of Spatial Planning, Environmental Planning and } \\
\text { Land Rearrangement }\end{array}$ \\
\hline $\begin{array}{l}\text { Environmental } \\
\text { planning }\end{array}$ & $\begin{array}{l}\text { Building and operating DHS has an environmental impact that is } \\
\text { a key issue of this research and is therefore considered. }\end{array}$ & BOKU-IRUB \\
\hline $\begin{array}{l}\text { Energy } \\
\text { technology }\end{array}$ & $\begin{array}{l}\text { Also, energy aspects play an important role when analysing DHS, } \\
\text { e.g. chosen energy sources, grid design, and new developments } \\
\text { regarding renewable sources. }\end{array}$ & AEA—Austrian Energy Agency, Vienna \\
\hline $\begin{array}{l}\text { Buildings } \\
\text { technology }\end{array}$ & $\begin{array}{l}\text { Thermal quality of buildings, needed temperature levels, applied } \\
\text { heating distribution systems, and new developments are } \\
\text { essential to understand the heat demand side. }\end{array}$ & AEA \\
\hline $\begin{array}{l}\text { Resource } \\
\text { management }\end{array}$ & $\begin{array}{l}\text { For constructing DHS, materials for plants, grids, storages, etc. are } \\
\text { needed. }\end{array}$ & RMA—Resources Management Agency, Vienna \\
\hline
\end{tabular}

performed within the research team as well as with an advisory board. Finally, overall planning principles are derived from the findings. The following subsections describe the first three methodological steps in more detail, while step 4 will be performed within the 'Discussion' section of this paper.

\section{Identification of parameters}

In a first step, relevant parameters for DHS were collected by experts in the fields of spatial planning, environmental planning, energy technology, buildings technology, and resource management. Table 1 illustrates the motivation for the inclusion of the aforementioned disciplines and links them to the responsible institutions within this research project.

Based on a disciplinary literature review and experience from previous projects, an interdisciplinary list of parameters was identified. Based on these literature reviews, all together, 55 parameters were identified, referring to all of the aforementioned disciplines. To reduce complexity and to facilitate further analyses, the set was narrowed down to finally 31 parameters by determining the relevance of each individual parameter within the research team (see Table 3 in the 'Results' section). For all 55 parameters, an impact analysis was performed; monomial impacts were taken into account, while impacts of higher order were neglected. If two or more parameters showed a similar impact, the most universal or meaningful one was selected (e.g. instead of 'total lifetime of the grid' and 'age of the grid', the 'remaining lifetime of the grid' was considered). Parameters for which a poor data availability was assumed (such as 'future subsidies' or 'price development of energy sources', 'interest rates') were also taken from the list. During the whole project, an intensive involvement of an advisory board took place, consisting of one senior expert of each of the institutions shown in Table 2. The advisory board was already included when designing the project. All members provided letters of intent showing that the project idea was acknowledged and supported by these relevant institutions. Based on the identified set of 31 system parameters, the pairwise influence of parameters on each other was analysed according to the method after F. Vester.

\section{System analysis after Vester}

The system analysis after Vester ([26-29]) is a system analytic method of characterizing the influence of parameters on a system, like on a DHS. It was developed in the 1970s and is designed to (a) gain an overview over relations within complex systems, (b) to clarify cause-and-effect chains between identified parameters, and (c) to encourage networked thinking. In this research, it is used to take a comprehensive look on DHS as it allows evaluating the influence of the 31 system parameters on each other in order to identify the system drivers and to get an overview over possible indicators.

To perform the method after Vester, the already identified system parameters are needed (described in the 'Identification of parameters' section) in order to (a) illustrate the pairwise interactions between those parameters and (b) evaluate the overall result.

\section{Identification of pairwise interactions between system parameters}

Before performing the system analysis, all selected parameters are put into a matrix. Hereinafter, the influence of each parameter in the row on each parameter in the column is evaluated. After doing this for all $n x(n-1)$ combinations, the sums in each row ('active sum') and in each column ('passive sum') are calculated to analyse how much the system parameters influence the system and are influenced within the system. Accordingly, the active sum refers to the number of parameters on which a certain parameter has an impact, whereas the passive sum corresponds to the number of parameters which influence a certain parameter. To describe the concrete influence, three different approaches exist, which either 
Table 2 Member institutions of the advisory board

\begin{tabular}{ll}
\hline Institution (name in German) & Field of work \\
\hline City of Vienna, MA 20 & Energy Planning Department of the Vienna City Administration \\
Wien Energie & $\begin{array}{l}\text { Company operating power plants (CHP, waste incineration, biomass, photovoltaics, wind, etc.) of several } \\
\text { kinds and sizes; main energy provider in Vienna }\end{array}$ \\
$\begin{array}{l}\text { Wiener Netze } \\
\text { Responsible for the design and maintenance of the Vienna district heating, gas, and electricity grid }\end{array}$ \\
$\begin{array}{l}\text { Cities and Towns) } \\
\text { Grazer Energieagentur }\end{array}$ \\
$\begin{array}{l}\text { Land Salzburg (Department of covering around 50\% of the Austrian population } \\
\text { Economics) }\end{array}$ \\
$\begin{array}{l}\text { Expertise through several scientific projects about district heating } \\
\text { Responsible for the provincial energy strategy; energy consulting with respect to renewable energies and } \\
\text { energy performance certificates in the province of Salzburg }\end{array}$
\end{tabular}

correspond to the original method of Vester or represent modifications:

- Version 1: The strength of influence is assessed by using a classification (very strong, strong, low, no influence, etc.) (Fig. 2a) [29].

- Version 2: The strength of influence is replaced by the direction of influence (Fig. 2b) (own considerations after $[29,30])$.

- Version 3: The strength and the direction of influence are not relevant. It is only stated whether there is an influence or not (Fig. 2c) [30].

Version 1 represents the original method according to Vester. This version had been criticized in the literature as the ratings for the strength of influence are ordinal data and therefore unsuitable for calculations. Still, additions and divisions were performed ([21, 31]). Version 2 replaces the ratings of strength by the direction of influence. It is important to define the meaning of 'positive' and 'negative', e.g. for 'economic feasibility'. For some parameters, this is impossible, e.g. 'building type' or 'construction material', while others can be evaluated in this way. Version 3 represents a simplified method (Fig. 2c), taking the former critics into account by only indicating the existence or absence of influence by inserting ' 1 ' (influence) resp. '0' (no influence).

To avoid the highlighted problems regarding versions 1 and 2, version 3 was chosen for further research. At first, the matrix was filled by each of the research groups separately. Grid cells where all research groups obtained the same result were directly adopted for the final result and not further discussed; if the result was not consensual, each of the impacts was discussed until a consensus was reached. Finally, the impact analysis was discussed and confirmed by the advisory board. In this way, a consensus for all system parameter combinations was obtained. Different results can be reasoned as follows: (a) different expertise of the experts, (b) different understanding of the parameters' definition (can be minimized by precise definitions), and (c) neglecting small or second order influence (A influences B; B influences $\mathrm{C} \rightarrow \mathrm{A}$ influences $\mathrm{C}$ ).

\section{Evaluation of the results}

In a set of 31 system parameters, each can influence between 0 and 30 other parameters and can also be influenced by 0 to 30 parameters. Hereby, four types of parameters can be defined using the method after Vester:

\begin{tabular}{|c|c|c|c|c|}
\hline $\mathrm{a}$ & 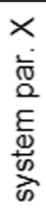 & 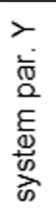 & 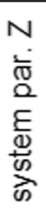 & 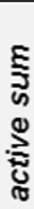 \\
\hline system par. X & & 0 & 1 & 1 \\
\hline system par. $Y$ & 3 & & 1 & 4 \\
\hline system par. Z & 0 & 4 & & 4 \\
\hline passive sum & 3 & 4 & 2 & \\
\hline
\end{tabular}

\begin{tabular}{|c|c|c|c|c|}
\hline$b$ & 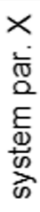 & 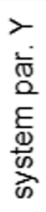 & $\begin{array}{l}N \\
\frac{1}{0} \\
\alpha \\
\frac{E}{\alpha} \\
\frac{d}{\omega} \\
\text { क }\end{array}$ & 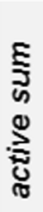 \\
\hline system par. X & & 0 & $\uparrow$ & 1 \\
\hline system par. Y & $\downarrow$ & & $\uparrow$ & 2 \\
\hline system par. Z & 0 & $\downarrow$ & & 1 \\
\hline passive sum & 1 & 1 & 2 & \\
\hline
\end{tabular}

\begin{tabular}{|c|c|c|c|c|}
\hline C & 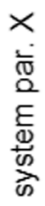 & 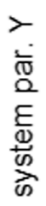 & 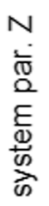 & 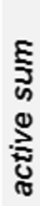 \\
\hline system par. X & & 0 & 1 & 1 \\
\hline system par. Y & 1 & & 1 & 2 \\
\hline system par. Z & 0 & 1 & & 1 \\
\hline passive sum & 1 & 1 & 2 & \\
\hline
\end{tabular}

Fig. 2 System analysis by F. Vester. a The strength of influence (version 1). b The direction (positive ( $\uparrow$ ) or negative ( $\downarrow$ )) of influence (version 2). c The existence of influence (version 3). par., parameter; red arrow, evaluation of the influence of one system parameter (in the row) on another (in the column) (own illustration) 
- Active parameters: influencing the majority of other system parameters but influenced only by a minority of them

- Passive parameters: influencing only a minority of other system parameters but influenced by the majority of them

- Critical parameters: influencing the majority of other system parameters and also influenced by the majority of them

- Buffering parameters: influencing only a minority of other system parameters and also influenced only by a minority of them

Each of the four categories has certain characteristics of influence; a change of active parameters shows a large impact on the whole system. As they are not influenced by many other parameters, they will remain mostly stable when other system parameters change. Still, they can be changed directly, e.g. by policymakers. A change of critical parameters also shows a large impact on the system, but as they are influenced by a lot of other parameters, it is harder to predict their changes and therefore their impact on the whole system.

On the contrary, passive parameters can be used as 'indicators' as they react sensitively on changes of the other system parameters. Still, not all passive parameters can be taken as indicators as many of them are very specific and therefore not suitable for a general analysis. Buffering parameters can be seen as stabilizers of the system, but if AS and PS are both very low, they could also be excluded from the system analysis as they hardly interact with the particular research topic.

Following this differentiation into four types of parameters, the relevant parameters can be clustered into 'system drivers' and 'indicators'. In order to actively induce changes within DHS, the identified active and critical parameters are of primary interest. Together, they form the group of 'system drivers'. They can be changed by policymakers through adapted spatial planning strategies and building insulation policies and influence the 'indicators'.

'Indicators' are important as they describe how the system will change. However, their identification is not as clear as that of the system drivers. In principle, they should be found among the passive parameters, while in some cases, buffering parameters especially influenced by active and critical parameters are of additional interest. It is important to focus on the most important indicators; otherwise, the total influence on the system cannot be assessed. At the first stage, passive and buffering parameters together shall build the group of 'potential indicators'. In the second step, each of those is analysed separately in order to derive a final set of indicators. The environmental and economic feasibility parameters themselves shall not be considered as indicators, because indicators are understood as influence factors which indicate the environmental and economic feasibility (and not describe them directly). Furthermore, individual parameters and parameters that show no direct influence on DHS as well as those containing information that is obtained by other parameters should not be considered. Especially, if a lot of influence factors can only be assessed qualitatively, an overall effect on the system can only be identified with a small indicator set.

\section{Scenarios for DHS until 2050}

A crucial question is the long-term feasibility of DHS with respect to several changes until 2050. As DHS are long-term investments, but framework conditions can change rapidly, it is important to understand future developments. Therefore, for each of the system drivers (or compatible groups), a scenario is defined. Estimated future trends are based, wherever possible, either on recent developments or on existing scenarios resp. prognoses; otherwise, expert judgements have to be made. As the impact on DHS can only be assessed via indicators (parts of the passive and buffering parameters of the Vester analysis), the impact of the identified system drivers on these indicators is defined. In the end, an overall impact on each indicator is assessed from the single impacts of the system drivers. The results for the indicators can be summarized in order to obtain a full picture of the future environmental and economic feasibility of DHS.

However, fluctuating parameters like prices cannot be included as they are too speculative. Impacts that can be assessed by numbers will be calculated, and the other types of influence will be discussed qualitatively to give a complete picture of the possible directions of future changes.

\section{Results \\ Identification and evaluation of parameters}

After collecting influencing factors from the research groups and narrowing down the set to the most important influence factors, 31 system parameters were obtained.

Table 3 shows all 31 parameters identified in the analysis on DHS. Furthermore, the table indicates the existence respectively absence of interactions between the 31 parameters (see also 'Identification of pairwise interactions between system parameters' section).

\section{System drivers}

After identifying and evaluating the parameters, they can be clustered into 'system drivers', 'indicators', and 'neither system drivers nor indicators'. To start this classification, the original Vester method is followed and explained in the 'Evaluation of the results' section (see Fig. 3). The right half of Fig. 3 displays the active and critical 


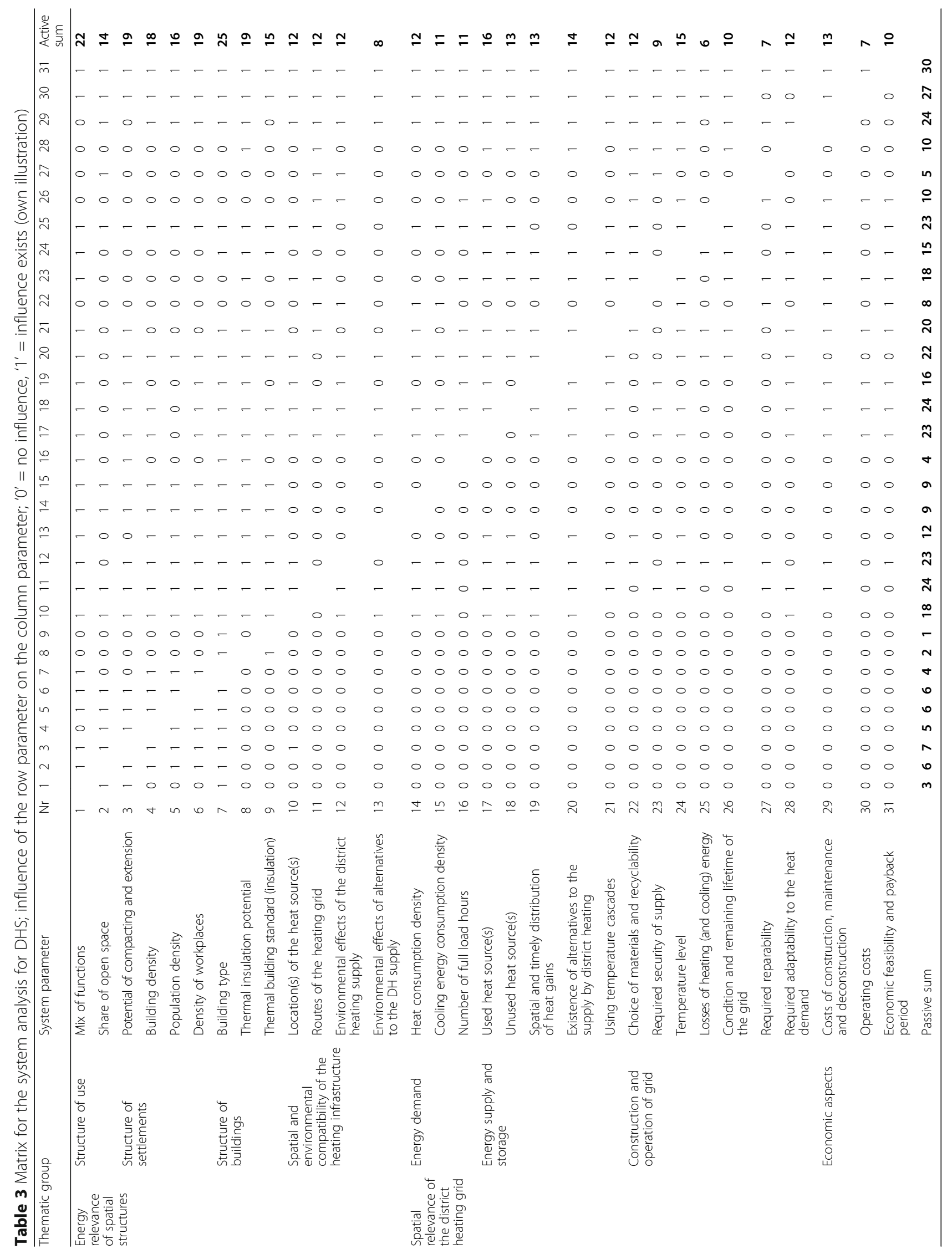


parameters (system drivers) which are of special importance when analysing the evolution of existing DHS grids as well as for constructing new ones. In the following, the system drivers are described and ranked according to their active sum (AS) (if equal, then according to their passive sum (PS) in increasing order). The maximum value for both active and passive sum is 30 .

Based on the adapted system analysis after Vester (Version 3, see the 'Identification of pairwise interactions between system parameters' section), eight system drivers were identified among the 31 system parameters, which show the most impact on the other system parameters. Due to their importance, they are described separately in more detail:

(I) Building type ( $\mathrm{AS}=25$; $\mathrm{PS}=4$ ) examples are residential, industry, office, hospital, retail, agriculture, etc. They lead to different energy consumption profiles and therefore affect the environmental and economic feasibility of DHS.

(II) Mix of functions ( $\mathrm{AS}=22$; $\mathrm{PS}=3$ ) describes the spatial mix of building functions. Different forms of use of buildings are residential, working, leisure, culture, education, industry, mobility, communication, etc. Each of those shows specific load profiles. The mix of functions leads to a mix of load profiles which enlarges the number of annual full load hours. Therefore, by mixing functions, investments into DHS pay off easier and the need for heat storages is reduced. Different mixes of functions show different effectiveness regarding the increase of full load hours [4]. Different needed temperatures within one grid tend to necessitate higher net temperatures as they have to be adapted to the highest temperature demand (not applicable to low-temperature grids with decentralized heat pumps). This can exclude low-temperature sources and cause higher net losses, but giving the potential of using cascades. Further effects of mixed functions are shorter distances between living, working, shopping, and leisure as well as possible user conflicts (noise, pollution, etc.).

(III)Thermal insulation potential $(\mathrm{AS}=19 ; \mathrm{PS}=2)$ defines the potential of enhancing the thermal insulation quality of buildings, leading to a reduced heating energy consumption. This parameter especially affects long-term feasibility. Depending on the type and age of supplied buildings, insulation potential can vary. Monument conservation is a factor reducing the thermal insulation potential; another is economic feasibility. Saving effects are often lower than expected due to rebound effects (users tend to increase temperatures or start to heat unneeded rooms, etc.) [32].
(IV)Density of workplaces (AS = 19; PS = 6) indicates the number of workplaces per area. A definition using the full-time equivalents is more appropriate, still leaving an uncertainty due to diverse types of working places and related energy use, varying widely between offices (low energy consumption) and steelworks (high energy consumption). This parameter summarizes the energy consumption of nonresidential buildings, while 'Population density' that of residential buildings.

(V) Potential of compacting and extension (AS = 19; $\mathrm{PS}=7$ ) means an increase of density, either square meter building areas per hectare or the number of inhabitants/hectare, workplaces/hectare, etc. This can be reached either by constructing new buildings, adding storeys to existing buildings, or reusing existing buildings [33]. It is an important factor for DHS as energy consumption density can be increased. It can also be understood as the potential of connecting buildings to an existing DHS. In [34], it was shown for 104 Chinese cities that cities with more centralized and compact urban forms show less $\mathrm{CO}_{2}$ emissions.

(VI) Building density (AS = 18; PS = 5) can be understood in two different ways. Karathanassi et al. [35] defined it as buildings' coverage percentage of the total surface, i.e. not taking building height into account. To classify areas according to their heat consumption, it makes more sense to define it as usable floor space of buildings in a defined surface area ([36], also providing a method of analysing the building density using LiDAR (Light detection and ranging) data).

(VII)Population density ( $\mathrm{AS}=16$; PS $=6$ ) refers to the number of inhabitants per area. As building use can differ (percentage of non-residential buildings area, floor space per person), densities of buildings and of inhabitants do not necessarily correlate; therefore, it is considered separately. It is also important as warm water energy consumption correlates with the number of persons and is responsible for an increasing percentage of domestic overall energy consumption due to higher building insulation standards. Taking other densities into account, e.g. of hotels, shopping centers, industrial workplaces, would give even more insight, but also increase the complexity. Densities of buildings, inhabitants, and employees shall be taken as representative.

(VIII) Used heat source(s) (AS = 16; PS = 23) means the primary energy sources that feed the DHS and is the only critical parameter found in the system analysis. In the environmental impact analysis, the used heat sources play a central role [3], because emissions vary significantly. Regarding the 


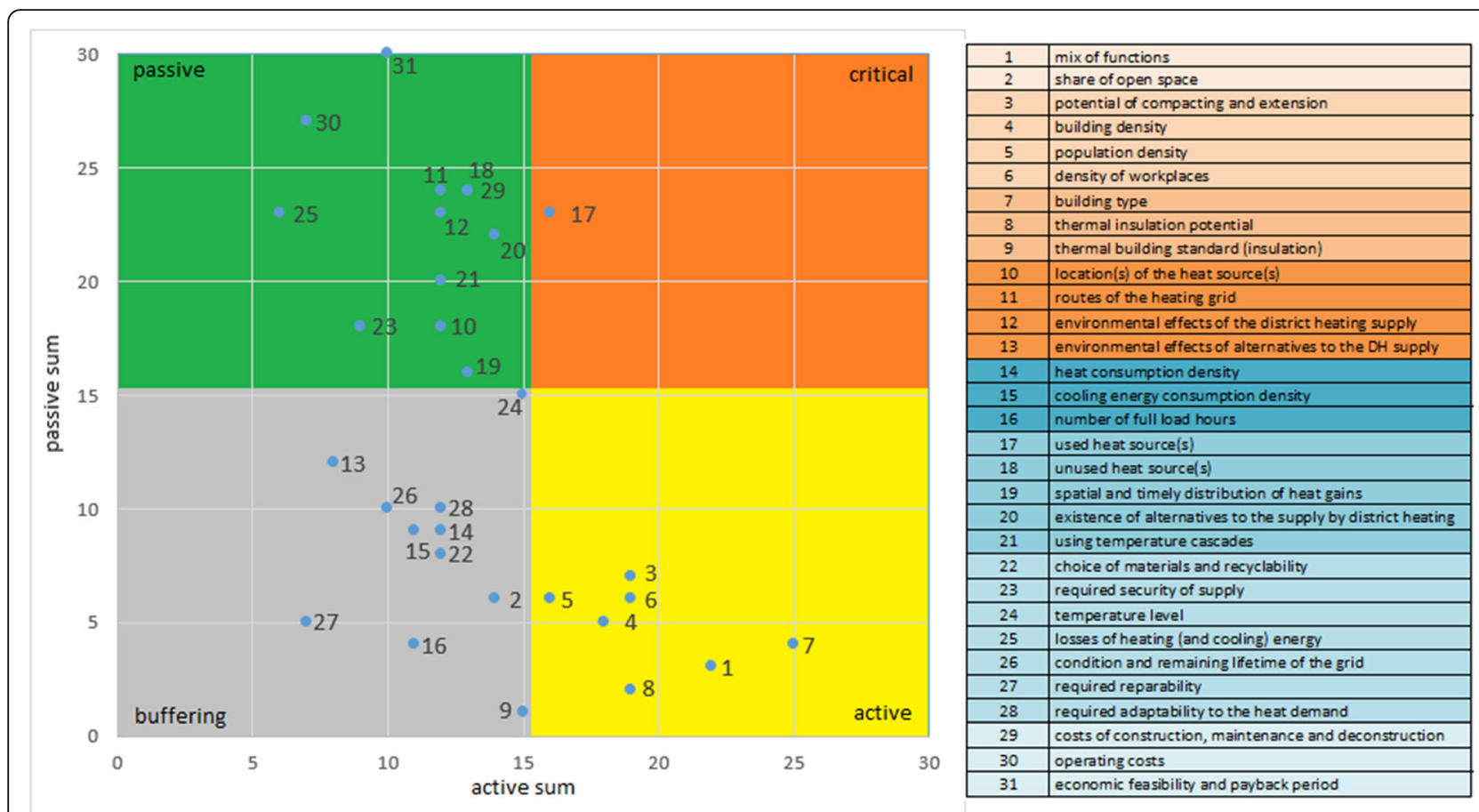

Fig. 3 Classification of the system parameters according to their active ( $x$-axis) and passive sum ( $y$-axis) into active, passive, critical, and buffering parameters. Numbers are in line with those in Table 3 (own illustration)

economic dimension of DHS, large price differences can occur, depending on the energy source as well as on the individual price a DHS operator has to pay (possibly time-dependent).

\section{Indicators}

Following the analysis of the eight relevant system drivers, influenceable indicators also play a decisive role for the long-term feasibility of DHS. However, the identification and evaluation of such indicators have no part in the original method after Vester. Therefore, we adapted the initial approach:

Referring to Fig. 3, passive and buffering parameters can be found on the left side of the illustration. Here, relevant indicators can be found, while it is important to identify the most important ones for further research. The environmental and economic feasibility parameters themselves shall not be considered as indicators, because indicators are understood as influence factors which indicate the environmental and economic feasibility (and not describe them directly). Other parameters are very individual, e.g. location of heat sources or routes of the heating grid, some show no direct effect on DHS, and some cover similar aspects like heat losses and temperature level. Table 4 gives an overview over all 31 system parameters and whether they were identified as system drivers, indicators, or neither one of both. The reasons why potential indicators were not further taken into account can be found in the right column.

Nineteen potential indicators were excluded while the following four indicators turn out to be a feasible approach for analysing the effects on the environmental and economic feasibility of DHS:

(1) Heat consumption density (AS = 12; PS = 9) describes the annual heat consumption per area or per grid length. DHS are characterized by relatively high investment costs. Moreover, the absolute heat losses in the grid increase with higher distances of heat transport. This shows that a high heat consumption density is of advantage both for the environmental and economic feasibility of a DHS (less heat dissipation in relation to the distributed heat and less material and construction effort for installing grids). Higher heat consumption in a smaller area means that for distributing a certain amount of heat, a shorter grid length is necessary. The heat consumption per area is a product of building density and specific heat consumption per floor space. It is clearly not desirable to actively increase the specific heat consumption per floor space. This means that in order to enhance the environmental and economic framework conditions for DHS, spatial planning policies must seek to reach adequate building densities. To secure high 
living quality especially in residential areas, density should stay modest.

(2) Full load hours (AS = 11; PS = 4) describe the quotient of annual energy consumption and maximum heat load. A higher heat load at a given annual energy consumption makes higher heat production capacities necessary. Also, the grid has to be designed for the maximum needed heat power (pumps, diameters of pipes including insulation, etc.). Therefore, the number of full load hours should be high. It depends on the heat consumption curve of the collective of heat consumers. The mix of functions has a huge impact on this parameter, while areas with domestic households have 2000 full load hours per year and less, multi-functional areas reach about 4500 [11].

(3) The available heat sources ( $\mathrm{AS}=15$; PS $=24$; as a combination of used and unused heat sources) affect the energy prices as well as the emission factors and are therefore relevant for the environmental and economic feasibility of DHS. Most renewables (like solar energy or heat pumps using ambient sources) are only accessible if grid temperatures in DHS are lower than in most grids currently in operation.

(4) The temperature level (AS = 15; PS = 15) depends on the purpose of heat (industrial-depending on the branch, residential heating-high and low temperature, warm water, etc.). If different heat consumers within a DHS require different temperature levels, the return flow of the higher temperature heat consumer can serve as the inlet flow of the lower temperature heat consumer (temperature cascade). This concept enlarges the spread between inlet flow and return flow of the district heating power plant making the grid more effective (higher potential of heat consumption can be covered by the grid) and more efficient (the ratio between electric energy for pumping and useful energy output at the consumers' sites decreases). Accordingly, combining different forms of building use (residential, commercial, and industrial-ideally different branches) increases the number of full load hours and potentially the temperature spread between the inlet and return flow. It is the result of a good spatial planning strategy to care for well-mixed quarters. The trend towards lower temperatures was already shown, and efforts are being made towards reducing return temperatures in existing grids [37].

Indicators 1,2 , and 4 can be found among the buffering parameters (Fig. 3). Two of them are only influenced by spatial parameters, which shows the great influence of spatial aspects on DHS. The available heat sources are a combination of used and unused heat sources; the average of their AS and PS gives a passive parameter.

In order to assess the future environmental and economic feasibility of DHS, the influence of the 8 system drivers on the 4 indicators is pointed out (Table 5). It has to be noted that the set of identified system drivers is able to influence the most relevant indicators identified by this research.

\section{Scenarios for DHS 2050 for Austria}

For assessing future challenges of DHS, realistic changes of the system drivers are set and the influence on the indicators is assessed. Expected trends until 2050 within large and mid-sized cities in moderate climates are included. Only those effects are analysed which are marked in Table 5.

\section{Scenario 1-increased density}

Three density parameters are among the system drivers (IV, VI, and VII). This indicates high importance of density as it influences the energy consumption density and in parts the available heat sources. (The effect of 'compacting and extension' as another density-related parameter shall be included in this scenario as well. However, its effect on the energy consumption density and available heat sources is covered by the effects of changed density. Its effect on the annual full load hours depends on the accompanied change in the mix of functions which will be discussed in the 'Scenario 4-mix of functions/building type' section.) As for population density, future trends are well documented, and this single density parameter shall be taken as a representative also for the others. In the past years, not only Austria as a whole but especially urban regions showed an increase of inhabitants $([16,38])$, being in line with the trend in many European and worldwide countries [39].

If the settlement boundaries are conserved and growth can be managed only by compacting existing areas, population growth and density of inhabitants' growth will correlate 1:1. Between 2017 and 2050, population of large Austrian cities will grow by about $10 \%$. Limited availability of development areas and an increasing number of inhabitants will lead to the necessity of increased building density. It can be assumed that the needed area for workplaces goes in line with an increased number of inhabitants. Concluding, the increase of density may have effects on indicators 1 and 3 (Table 6), while indicators 2 and 4 are not affected according to Table 5 .

\section{Scenario 2-thermal insulation potential}

Reacting to climate change and the limited resource availability, countries have introduced minimum thermic insulation requirements for new and refurbished buildings. 
Table 4 Summary of all system parameters and their classification after the system analysis (own illustration)

\begin{tabular}{|c|c|c|c|c|c|}
\hline Number & System parameter & AS & PS & $\begin{array}{l}\text { Category in system } \\
\text { analysis }\end{array}$ & Comment \\
\hline 1 & Mix of functions & 22 & 3 & Active & Driver II \\
\hline 2 & Share of open space & 14 & 6 & Buffering & Effect is covered by heat consumption density \\
\hline 3 & Potential of compacting and extension & 19 & 7 & Active & Driver $\mathrm{V}$ \\
\hline 4 & Building density & 18 & 5 & Active & Driver VI \\
\hline 5 & Population density & 16 & 6 & Active & Driver VII \\
\hline 6 & Density of workplaces & 19 & 6 & Active & Driver IV \\
\hline 7 & Building type & 25 & 4 & Active & Driver I \\
\hline 8 & Thermal insulation potential & 19 & 2 & Active & Driver III \\
\hline 9 & Thermal building standard (insulation) & 15 & 1 & Buffering & Effect is covered by heat consumption density \\
\hline 10 & Location(s) of the heat source(s) & 12 & 18 & Passive & Depending on local situations, not generically operable \\
\hline 11 & Routes of the heating grid & 12 & 24 & Passive & Depending on local situations, not generically operable \\
\hline 12 & $\begin{array}{l}\text { Environmental effects of the district heating } \\
\text { supply }\end{array}$ & 12 & 23 & Passive & $\begin{array}{l}\text { Depending on local situations, not predictable, not } \\
\text { generically operable }\end{array}$ \\
\hline 13 & $\begin{array}{l}\text { Environmental effects of alternatives to the } \\
\text { DH supply }\end{array}$ & 8 & 12 & Buffering & $\begin{array}{l}\text { Depending on local situations, not predictable, not } \\
\text { generically operable }\end{array}$ \\
\hline 14 & Heat consumption density & 12 & 9 & Buffering & indicator 1 \\
\hline 15 & Cooling energy consumption density & 11 & 9 & Buffering & Included in heat consumption density and temperature level \\
\hline 16 & Number of full load hours & 11 & 4 & Buffering & Indicator 2 \\
\hline 17 & Used heat source(s) & 16 & 23 & Critical & Driver VIII, part of indicator 3 \\
\hline 18 & Unused heat source(s) & 13 & 24 & Passive & Part of indicator 3 \\
\hline 19 & Spatial and timely distribution of heat gains & 13 & 16 & Passive & Not stable, not predictable, not generically operable \\
\hline 20 & $\begin{array}{l}\text { Existence of alternatives to the supply by } \\
\text { district heating }\end{array}$ & 14 & 22 & Passive & Depending on local situations, not predictable \\
\hline 21 & Using temperature cascades & 12 & 20 & Passive & Effect is covered by temperature level and full load hours \\
\hline 22 & Choice of materials and recyclability & 12 & 8 & Buffering & $\begin{array}{l}\text { Individual decision of grid operator, not predictable, not } \\
\text { generically operable }\end{array}$ \\
\hline 23 & Required security of supply & 9 & 18 & Passive & $\begin{array}{l}\text { Individual decision of grid operator, not predictable, not } \\
\text { generically operable }\end{array}$ \\
\hline 24 & Temperature level & 15 & 15 & Buffering & Indicator 4 \\
\hline 25 & Losses of heating (and cooling) energy & 6 & 23 & Passive & $\begin{array}{l}\text { Effect is covered by heat consumption density and } \\
\text { temperature level }\end{array}$ \\
\hline 26 & Condition and remaining lifetime of the grid & 10 & 10 & Buffering & Individual situations, not generically operable \\
\hline 27 & Required reparability & 7 & 5 & Buffering & Individual situations, not generically operable \\
\hline 28 & Required adaptability to the heat demand & 12 & 10 & Buffering & Individual situations, not generically operable \\
\hline 29 & $\begin{array}{l}\text { Costs of construction, maintenance, and } \\
\text { deconstruction }\end{array}$ & 13 & 24 & Passive & Not stable, not predictable, not generically operable \\
\hline 30 & Operating costs & 7 & 27 & Passive & Not stable, not predictable, not generically operable \\
\hline 31 & Economic feasibility and payback period & 10 & 30 & Passive & Not stable, not predictable, not generically operable \\
\hline
\end{tabular}

Numbers in the left column correspond to those in Fig. 3 and Table 3

In Austria, the thermal refurbishment rate of the building stock is around $1 \%$ per year [40]. Taking into account a constant insulation rate until 2050, a decreased building energy consumption by $50 \%$ and a reduction of $16 \%$ of energy consumption in the building stock are realistic.

Depending on the climate change scenario (see the 'Scenario 3-climate change' section), the heat consumption of non-residential buildings of different building ages will be reduced by up to $30 \%$ until 2050, while cooling energy consumption will nearly double, especially for older buildings [41]. Therefore, district cooling will become more important, while district heating could, together with the impact of global warming, lose importance. Local generation potentials like (building integrated) photovoltaic (PV) in combination with power-to-heat solutions (via electric resistance or heat pump heating) reduce the heat 
demand additionally. The power resp. energy output of realized installations in the future is hardly quantifiable, but must be kept in mind as a district heating grid planner. Still, the absolute values of heat consumption will not necessarily decrease because of increasing numbers of inhabitants. As shown in Table 5, the thermal insulation potential affects all four indicators. The concrete effects are described in Table 7.

\section{Scenario 3-climate change}

Climate monitoring shows that the increase of temperature between 1880 and 2014 in Austria amounts to $2{ }^{\circ} \mathrm{C}$ ([43], p.267). Higher temperatures obviously lead to a lower heat energy consumption density. The number of heating degree days in Austria from 2010 to 2050 will decrease from 3252 to 2907 (-10.6\%) [44]. Referring to the four indicators, indicators 1,2 , and 4 will be affected by climate change (Table 8 ).

\section{Scenario 4-mix of functions/building type}

The future development of the mix of functions depends on the political framework conditions, especially regarding spatial planning policies. However, no prognoses exist. Still, it can be estimated that spatial planning will have an increasing impact as in the last years the topic found its way into central national and international climate policy papers. Therefore, the influence of an increasing mix of functions shall be estimated (Table 9). As the building type and its functions are very much aligned, the effects on the indicators correlate and the effects of the building type are not discussed separately.

\section{Effects of future scenarios on the four indicators}

After the separate analysis of the four scenarios, a summary of the changes on the indicators for DHS until 2050 can be given. It has to be mentioned that the scenarios were discussed in the light of the system drivers, whereas the impacts on the DHS have to be discussed considering the influences on the indicators. Therefore, from each scenario, the impacts per indicator are collected and put together in Table 10.

Total heat consumption density will decrease by approximately $16 \%$ on average in existing settlements. This means a negative impact on the future feasibility of DHS. The effect on the economic feasibility of DHS depends on the present market share and on the accepted cost level [18]. However, values are highly variable locally. An increase of about $8 \%$ of the number of annual full load hours can be estimated, which means a positive impact on the future feasibility of DHS. Furthermore, a larger variety of available heat sources is expected. Finally, a slight decrease in the main needed temperature level is expected, which goes in line with a larger variety of heat sources.

However, the overall effect on the environmental and economic feasibility of DHS will depend on the local circumstances, but the results show that decreasing energy consumption does not seem to be a big threat for DHS in the future as it will be balanced by three other positive impacts.

\section{Discussion}

In the discussion, the findings of this research are highlighted from different perspectives while the first three research questions will be answered. Hereinafter, the applied methods, their benefits, and possible shortcomings are discussed. Finally, we derive planning principles and recommendations from our findings.

\section{System drivers and indicators of DHS}

A central outcome of the research is the identification of the most relevant system drivers on a DHS and of the most representative indicators that describe their influence. Regarding the whole set of parameters identified as relevant for DHS, there are two main groups. The first one is the parameters of the DHS itself, mainly the heat sources, heat generation sites, grids, storages, heat losses, etc. The second one regards systems interacting

Table 5 Influence of the system drivers on the indicators of the DHS extracted from Table 3 (own illustration)

\begin{tabular}{|c|c|c|c|c|c|}
\hline \multirow{2}{*}{\multicolumn{2}{|c|}{$\begin{array}{l}\text { Parameters referring to technical aspects of the } \\
\text { DHS and spatial planning }\end{array}$}} & \multicolumn{4}{|l|}{ Indicators } \\
\hline & & $\begin{array}{l}\text { (1) Energy consumption } \\
\text { density }\end{array}$ & $\begin{array}{l}\text { (2) Number of full load hours } \\
\text { per year }\end{array}$ & $\begin{array}{l}\text { (3) Available heat } \\
\text { source(s) }\end{array}$ & $\begin{array}{l}\text { (4) Temperature } \\
\text { level }\end{array}$ \\
\hline \multirow{8}{*}{$\begin{array}{l}\text { System } \\
\text { drivers }\end{array}$} & (I) Building type & $\checkmark$ & $\checkmark$ & $\checkmark$ & $\checkmark$ \\
\hline & (II) Mix of functions & $\checkmark$ & $\checkmark$ & $\checkmark$ & $\checkmark$ \\
\hline & (III) Thermal insulation potential & $\checkmark$ & $\checkmark$ & $\checkmark$ & $\checkmark$ \\
\hline & (IV) Density of workplaces & $\checkmark$ & & $\checkmark$ & \\
\hline & $\begin{array}{l}\text { (V) Potential of compacting and } \\
\text { extension }\end{array}$ & $\checkmark$ & $\checkmark$ & $\checkmark$ & \\
\hline & (VI) Building density & $\checkmark$ & & $\checkmark$ & \\
\hline & (VII) Population density & $\checkmark$ & & & \\
\hline & (VIII) Used heat source(s) & & & $\checkmark$ & $\checkmark$ \\
\hline
\end{tabular}


with DHS like consumers, buildings, and their spatial distribution. In the course of the system analysis, it was shown that none of the parameters related to the first group is among the active parameters; only the used heat source(s) was a critical parameter. This means that by changing only the energy system, the chance of enhancement of the environmental and economic feasibility of a DHS is rather low, i.e. the way of planning district heating grids does not substantially affect their environmental and economic feasibility. On the contrary, environmental and economic feasibility are highly dependent on grid-external factors. In order to create a DHS-friendly environment, mainly those have to be taken into account, on one hand, the connected buildings, their density and their use, thermal standard, etc. are of relevance [45]. On the other hand, the spatial distribution of buildings and their different functions are important factors. Therefore, policies that focus on enhancing conditions for DHS have to consider the heat consumers and their spatial distribution. Policy issues relevant for DHS cover ownership structures, legal frameworks, pricing, and other issues like awareness raising campaigns and knowledge development [3].

Spatial planning policies can build upon these results. Increasing building densities and mix of functions as well as using adjacent waste heat potentials will help ensuring that DHS will be able to operate economically and environmentally successfully also on a long-term scale [2]. Impacts that will occur (like climate change or thermal insulation of buildings) can be compensated by foresighted spatial planning strategies which allow mixing building functions or increasing density in a way that allows higher quality of life. This also affects other parts of the environment such as a reduction of traffic, accordingly the opportunity for inhabitants to save time, and a reduction of emissions and expenses for transport as well as an increase of quality of life. This means spatial planning strategies that are favourable for DHS also enhance the environmental and economic feasibility as well as the overall quality of systems in totally different topics.

It was shown that there is a certain risk for some DHS to stay economically feasible and competitive against the environmental impacts of alternative heating systems as the energy consumption density will decrease by about $16 \%$. Among others, the reduction is reasoned by enhanced thermal insulation and climate change. It can be estimated that despite all international agreements, climate change will inevitably take place and thermal insulation of buildings is in principle desirable (leaving behind issues about the sustainability of fossil-based insulation materials). Therefore, on a regional scale, these issues can or shall not be influenced in favour of DHS (means there is no reasonable option to increase heat consumption density within existing buildings). Positive influences can only be derived from increasing building density. The feasibility of this approach depends on the local circumstances.

The parameter of full load hours is essential to care for a stable heat load which means investments into the grid infrastructure pay off earlier. However, in systems with a large share of renewables, fluctuation of heat production and heat excess in summer will become more important issues. This means that full load hours nowadays mainly indicating the timely distribution of consumption will be accompanied by a factor indicating the timely distribution of the production side. For some sources such as solar thermal heat, there is no option to change the production profile, therefore either the consumption profiles are changed (possible through local storages) or the large storages within the grid have to be applied. The optimization of storage dimensioning and management will accordingly gain importance.

The variety of available heat sources is difficult to discuss on a general scale as the local availability is essential. However, it is clear that renewable sources have gained importance in the last years and decades and this trend will continue. Most of the renewable sources (except biomass and burned organic waste) are low-temperature sources. This is why the fourth indicator 'temperature level' is very much aligned to the available heat sources. The importance of new grid typologies with local heat pumps has already been highlighted. In existing quarters, it will be difficult to implement such systems as the heating system of the buildings has to be adapted, space for more heat pumps is required, and existing grids cannot be used since existing diameters are too small due to presently higher spreads between the inlet and return flow. Therefore, in the establishment phase, this technology will most probably be widely used in new urban quarters; in existing settlements, a smaller reduction of the inlet flow temperature is more realistic than a solution with the necessity of local heat pumps.

Moreover, the results of this research can be put into a calculation scheme which allows assessing the long-term

Table 6 Influence of increased density on the indicators (own illustration)

\begin{tabular}{|c|c|}
\hline Indicator & Influence of increased density \\
\hline $\begin{array}{l}\text { (1) Energy consumption } \\
\text { density }\end{array}$ & $\begin{array}{l}\text { If living space per person stays constant, the density of inhabitants will lead to a } 10 \% \text { increase of energy consumption } \\
\text { density. }\end{array}$ \\
\hline (3) Available heat source(s) & $\begin{array}{l}\text { In the course of increased density, the variety of available heat sources expands at least for waste heat potentials while } \\
\text { distances decrease. }\end{array}$ \\
\hline
\end{tabular}


Table $\mathbf{7}$ Influence of the thermal insulation potential on the indicators (own illustration)

\begin{tabular}{|c|c|}
\hline Indicator & Influence of thermal insulation potential \\
\hline $\begin{array}{l}\text { (1) Energy consumpt } \\
\text { density }\end{array}$ & $\begin{array}{l}\text { For existing domestic buildings, heat consumption density will decrease by around } 15 \% \text { (less than } 16 \% \text { as domestic } \\
\text { hot water energy consumption will approximately stay stable; process heat is not assessed). New buildings will have } \\
\text { a lower energy consumption which means that depending on the local circumstances (removing old buildings and } \\
\text { replacing by new ones vs. compacting), the effect can be higher or lower. However, an average of } 15 \% \text { shall be } \\
\text { estimated. }\end{array}$ \\
\hline $\begin{array}{l}\text { 2) Num } \\
\text { er yea }\end{array}$ & $\begin{array}{l}\text { Decreasing energy consumption by climate change reduces the number of annual full load hours [42]. This is a result } \\
\text { of lower energy consumption in general and therefore applicable for decreasing energy consumption due to thermal } \\
\text { insulation as well. The effect is not very high and not given for all scenarios either; not always a correlation can be } \\
\text { observed. A decrease of full load hours due to thermal insulation and climate change of around } 10 \% \text { is possible. }\end{array}$ \\
\hline (3) Available heat source(s) & \multirow{2}{*}{$\begin{array}{l}\text { The number of available heat sources increases with decreasing grid temperature. Thermal insulation of buildings can } \\
\text { contribute to a temperature decrease and therefore influence both indicators in a positive way, but as in } \\
\text { conventional grids the temperature is adjusted to the highest temperature need this effect might not be realizable. }\end{array}$} \\
\hline (2) & \\
\hline
\end{tabular}

feasibility of concrete DHS resp. projects. It should close the gap between just guessing and sophisticated calculation tools that can only be operated by experts with a lot of detailed data which is usually not available at or before the beginning of a project. The identified system drivers build a set of input parameters. Via calculating the indicators using the input parameters, an analysis is possible, whether a DHS can be environmentally and economically feasible. The most important research fields in this context are the spatial suitability, energy consumption, environmental feasibility $\left(\mathrm{CO}_{2}\right.$ footprint, etc.), economic analysis, and the materials' input. According to this approach, a tool was developed [46] and tested [47] regarding its functionality and usability towards the long-term feasibility of DHS. It can be expected that from this tool, the motivation to start dealing with district heating increases and projects especially in smaller communities can be developed.

\section{Benefits and limitations of the applied methods}

The central method for the system analysis is the methodology after F. Vester. This method allows revealing unexpected influence parameters on systems (like DHS) and overcoming usual views as the importance for the whole system is assessed via identifying pairwise impacts of parameters on parameters. During this process of evaluating influences, the risk of being biased is less as the variety of interrelations that have to be evaluated amounts to several hundreds.

The methodology of Vester ([26-29]) was analysed and adapted within the last years [21]. However, the method still shows some pitfalls: One potential risk exists at the beginning, when the set of parameters is defined, that some important parameters are neglected. This can be avoided by including experts from different research fields. Still, in this research, it can be criticized that climate change was not considered as separate system parameter since it was only implicitly included by the parameter of heat demand and cooling demand density; however, it was added in the scenario section as a result of a further literature research.

The method delivers a feasible approach to identify the system drivers-parameters which influence the majority of other system parameters can automatically be taken. However, until now, the method did not include the identification of the relevant indicators. It only gives hints on which parameters could be taken as indicators. According to the literature, especially passive parameters should be adequate indicators. On the contrary, in this research, suitable parameters were identified among the buffering parameters. The reason is that some buffering parameters were mostly influenced by the active parameters whereas some passive parameters were influenced by a higher quantity of parameters which were no active parameters themselves. Taking all buffering or even passive and buffering parameters as indicators would lead to a confusing picture, at least in the performed analysis 23 parameters could have been potential indicators. In this research, the potential indicators were analysed each for each, coming to a set of 4 relevant indicators which represent future trends in a sufficient and manageable way. To understand the influence of the identified system drivers in a more refined way, the identification of indicators is a crucial task. The approach specified in

Table $\mathbf{8}$ Influence of climate change on the indicators (own illustration)

\begin{tabular}{|c|c|}
\hline Indicator & Influence of climate change \\
\hline $\begin{array}{l}\text { (1) Energy consumption } \\
\text { density }\end{array}$ & $\begin{array}{l}\text { The effect on the energy consumption density is approximately proportional, slightly lower as hot water demand wil } \\
\text { not change, and is therefore set to }-10 \% \text {. }\end{array}$ \\
\hline $\begin{array}{l}\text { (2) Number of full load hours } \\
\text { per year }\end{array}$ & $\begin{array}{l}\text { The effect on available heat sources and grid temperature corresponds to the effect by the thermal insulation } \\
\text { potential. }\end{array}$ \\
\hline 4) Temperature level & \\
\hline
\end{tabular}


Table 9 Influence of change of mix of functions and building type on the indicators (own illustration)

\begin{tabular}{ll}
\hline Indicator & Influence of mix of functions/building type \\
$\begin{array}{l}\text { (1) Energy consumption } \\
\text { density }\end{array}$ & $\begin{array}{l}\text { The mean value of energy consumption density is not affected by rearranging functions; only on a local level } \\
\text { changes will take place. }\end{array}$ \\
$\begin{array}{ll}\text { (2) Number of full load hours } \\
\text { per year }\end{array}$ & $\begin{array}{l}\text { A better (higher) mix of functions can increase the number of annual full load hours significantly, from } 2000 \text { up to } \\
4500 \text { [1 1]. If spatial planning policies are effective enough, they can lead to a higher number of full load hours by } \\
\text { diversifying local functions. A concrete mean value of achievable increase is speculative, but may be set to 20\% } \\
\text { which is easily accessible within the mentioned range. }\end{array}$ \\
(3) Available heat source(s) & $\begin{array}{l}\text { The number of available heat sources will rise as the variety of waste heat sources within a certain radius increases. } \\
\text { (4) Temperature level }\end{array}$ \\
$\begin{array}{l}\text { Temperature level in mixed areas could rise as the grid has to be designed for the highest needed temperature. } \\
\text { However, if applying local high temperature heat pumps, those consumers could be supplied without affecting the } \\
\text { overall temperature. Temperature cascades could be used as well. Therefore, the effect of mix of functions on the } \\
\text { temperature level will depend on the local circumstances and the specific technical approach. }\end{array}$
\end{tabular}

this research helps to better understand how the relevant indicators can be identified in a general approach, taking into account the mentioned special importance of influence coming from system drivers.

Furthermore, there remains the question of the relevance of each parameter. If a parameter influences more relevant parameters among the system parameters, it should rather be categorized as 'active' or 'critical' than such parameters which influence less relevant parameters. This of course would increase the necessity to evaluate the importance of each system parameter, which depends very much on the expertise of the involved researchers. Classifying system parameters as important or less important brings new fuzziness into the analysis. An alternative approach would be to set thematic groups with equal number of parameters. As an example, total costs can be separated into investment costs, energy costs, and maintenance costs. The choice of either defining 'total costs' as a system parameter or 'investment costs', 'energy costs', and 'maintenance costs' would change the number of parameters influencing costs or being influenced by costs.

It is proposed not to set strict borders between the sub-categories 'active,' 'passive', 'critical', and 'buffering'. Rather, an overlap should be established ('to be further discussed') and the parameters within its borders should be analysed each for each. Subsequently, there would be another step of discussion needed. This proposed method can be shown at the example of the quadrant analysis in Fig. 4. The width of the section 'to be further discussed' in Fig. 4 was set to $15 \%$ of the overall width, but this is subject to an iterative process.

This proposed further discussion can be based on similarities between classified and unclassified parameters, and also, the position within the unclassified area can give a hint. Anyhow, the method of Vester is no mathematically precise way to analyse a system. It helps to understand how parameters interact with each other and should be applied for complex systems (e.g. DHS) bearing in mind its qualitative nature.

\section{Planning principles derived from the findings}

In the 'Results' section and the previous discussion, it was shown which changes affect the environmental and economic feasibility of DHS in a positive way. From these findings general planning principles regarding spatial structures, buildings, and grids can be deducted that are given in the following.

\section{Spatial planning aspects}

(a) Analyse the waste and renewable heat sources potentials in a region

It was mentioned that a higher variety of heat sources can enhance the environmental and economic feasibility of DHS. Often, non-fossil sources are unknown and therefore not considered. Local authorities shall investigate the potential of waste heat and renewables in their

Table 10 Estimated change the four indicators until 2050 considering different scenarios (own illustration)

\begin{tabular}{lllll}
\hline Scenarios & $\begin{array}{l}\text { Energy consumption density } \\
\text { until 2050 }\end{array}$ & $\begin{array}{l}\text { Annual full load hours } \\
\text { until 2050 }\end{array}$ & $\begin{array}{l}\text { Variety of available heat sources } \\
\text { until 2050 }\end{array}$ & $\begin{array}{l}\text { Temperature level } \\
\text { until 2050 }\end{array}$ \\
\hline $\begin{array}{l}\text { Density (building/population/ } \\
\text { workplaces) }\end{array}$ & $+10 \%$ & $\pm 0 \%$ & Increasing & No effect \\
$\begin{array}{l}\text { Thermal insulation } \\
\text { Climate change }\end{array}$ & $-15 \%$ & $-10 \%$ & Increasing & Decreasing \\
Mix of functions/building type & $\pm 0 \%$ & & Increasing & Decreasing \\
Total & $-10 \%$ & $+20 \%$ & Increasing & Diverse \\
\hline
\end{tabular}


area and make the use of identified sources in DHS obligatory if appropriate.

(b) Increase building density in a modest way

In growing urban areas, it makes more sense to increase the building density within the settlement borders than to extend the borders. This is beneficial for DHS and additional reasons such as the reduction of traffic and the conservation of land for other use, e.g. for agriculture.

(c) Enhance the mix of functions

A better mix of functions can make waste heat potentials available and increase the number of full load hours in order to use the grid capacity to a higher extent, which is favourable especially for the economic, but also for the environmental feasibility.

\section{(d) Connect different infrastructure systems}

A stable district heating (and cooling) grid offers new possibilities to deal with the volatility of renewable energy generation. For instance, the power to heat or cold solutions in smart grids might help to store locally available surplus electricity, e.g. from building-integrated PV generation. As pointed out before, spatial parameters determine the environmental and economic feasibility of DHS and therefore the options to connect different infrastructure systems along the DHS grid.

\section{Buildings' aspects}

(a) Implement low-temperature heating systems and domestic hot water heat pumps

Low-temperature heating systems allow heat grids to run on lower temperature making waste heat and renewable potentials easier to access and reducing heat losses.

(b) Make surplus energy available for the grid

Building technologies should be customized to the available framework conditions. When a grid is available, the spatiotemporal patterns of energy supply and demand should be optimized in relation to the grid.

\section{Planning of grids' aspects}

(a) Considering new grid typologies with disperse heat producers
Buildings can be adapted towards lower temperatures, but the grid has to take this opportunity; otherwise, renewable and waste heat potentials remain excluded. Therefore, larger diameters of pipes have to be foreseen and the opportunity for customers to feed in heat has to be secured. Moreover, seasonal storages can increase the potential of renewables as they are often available in summer while consumption occurs in winter predominantly.

With these planning principles, the complex interrelations between the spatial structures and district heating planning can be made operational. Spatial planners can be made aware that parameters of urban planning highly influence the possibilities of grid-bound heating and cooling supply. Assuming that such energy grids will also be essential in the future for integrating volatile renewable energy generation via power-to-heat and power-to-cold solutions, this contribution of spatial planning to the energy transition may not be underestimated. Energy planners are empowered to consider dynamics of the urban fabric where both changes in the existing building stock and of new developments in relation to available renewable energy sources and climate change impacts influence the future feasibility of district heating grids. How this system analysis can be transferred into a decision support model is described in [46]. Examples for application and lessons learned are presented in [47].

\section{Conclusion}

The crucial indicators for district heating systems (DHS) are 'energy consumption density', 'full load hours', 'temperature level', and 'usable heat sources'. They can be influenced by the active and critical system parameters (system drivers) 'mix of functions', 'potential of compacting and extension', 'building density', 'density of inhabitants,' 'density of employees,' 'building type,' 'thermal insulation potential', and 'used heat source(s)'. These parameters were identified in the system analysis after $\mathrm{F}$. Vester and describe the feasibility of future DHS.

While the energy consumption density will decrease in average due to climate change and thermal insulation of existing buildings until 2050 (new settlements are likely to have even lower energy consumption densities), the number of full load hours and the variety of usable heat sources will increase and temperature level is likely to decrease.

Newer (4th generation; [3, 22]) grid typologies running at low temperature with decentralized heat pumps also usable for cooling will gain importance [6]. Centralized heat production will be complemented by feeding in local heat sources, and thermal storages will gain importance [48]. Grid temperatures will decrease especially in new urban areas. For concrete DHS, changes until 2050 are more precisely quantifiable. According to the 


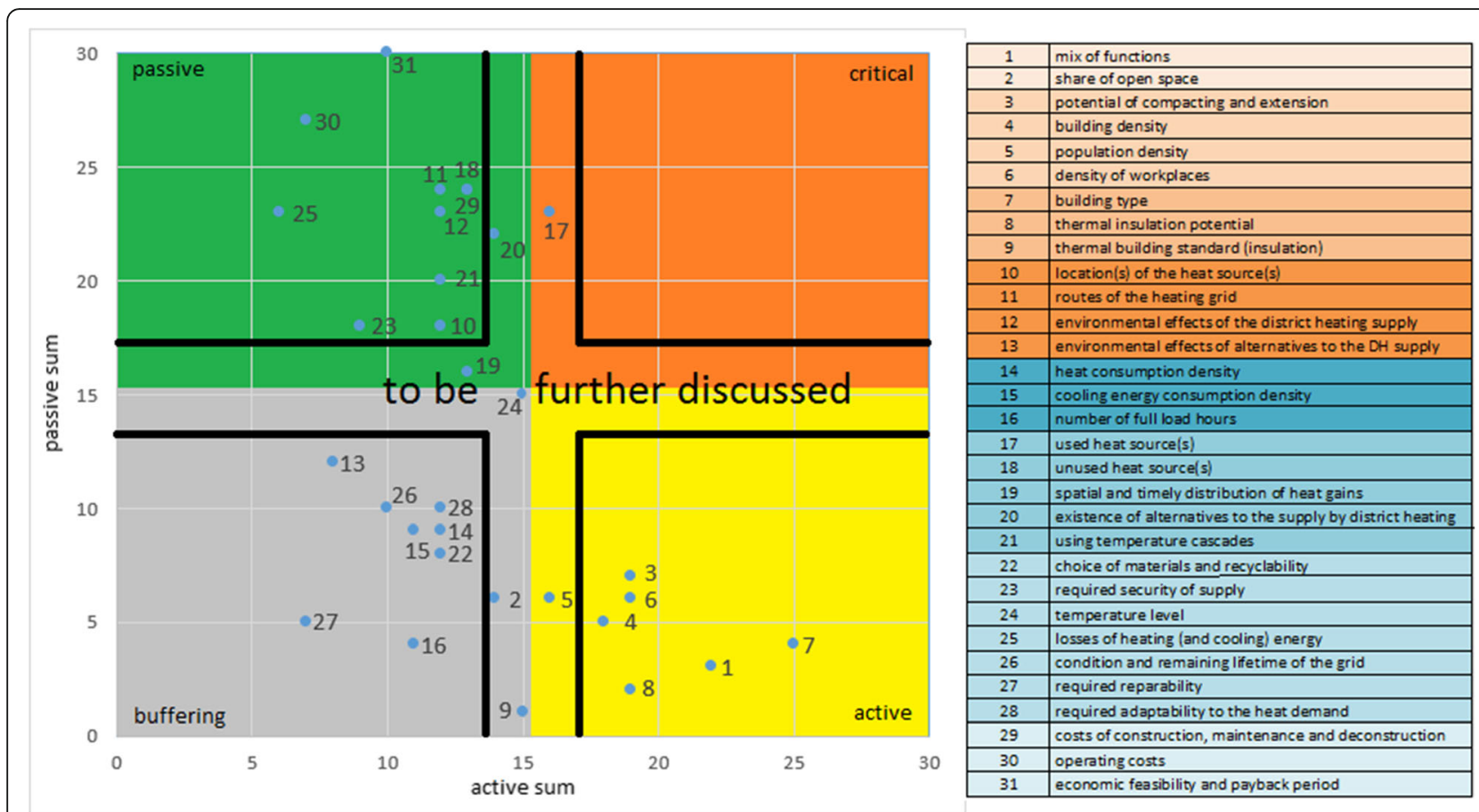

Fig. 4 Modified system analysis—-system parameters close to another quarter are not classified automatically

need for calculating long-term effects on DHS, research was recently done towards the development of a tool that shows the feasibility of DHS based on spatial, energy, material, and cost parameters ([46, 47]).

It was shown that there are a lot of reasons why DHS can be advantageous: connection between areas with thermal energy surplus and heat energy consumption, economies of scale and higher resilience due to less import dependency, and intensified use of local sources. Nevertheless, resource intensity of the infrastructure, heat losses in the grid, and highly insulated new buildings leading to low heat consumption densities set limits to the areas where DHS lead to environmental and economic benefits.

Knowing about locally available heat sources increases the variety of available energy sources, and constructing low-temperature heating systems in new and refurbished buildings will support especially the environmental feasibility of DHS. The design of grids will have to adapt to these changes where necessary. Moreover, spatial planning turns out to be a central policy issue. By compact, densely built settlements with a good mix of functions, the framework conditions for DHS can be enhanced essentially. It will depend on the future spatial planning policies how large the share of DHS in the heating energy market will be. Nevertheless, DHS will remain environmentally and economically feasible in the future, especially in densely built quarters with already existing buildings.

\section{Endnotes}

${ }^{1}$ The term 'anergy grids' is also frequently used; however, from a physics point of view, this term does not make sense.

\section{Abbreviations}

a: Year; AS: Active sum; CHP: Combined heat and power; $\mathrm{CO}_{2}$ : Carbon dioxide; DHS: District heating systems; PS: Passive sum; PV: Photovoltaic; PVT: Photovoltaic-thermal

\section{Acknowledgements}

The authors would like to thank the entire project team of 'Eco.District.Heat' as well as the Advisory Board Members for the accompaniment of the research processes. Findings, conclusions, and recommendations within this paper reflect results of the original study and represent a content-related development and post-processing of research results.

\section{Funding}

This research took place within the publicly funded research project 'Eco.District.Heat' and was funded by the Austrian Ministry of Transport, Innovation and Technology (BMVIT) within the programme 'Stadt der Zukunft'.

\section{Availability of data and materials}

All data generated or analysed during this study are included in this published article.

\section{Authors' contributions}

FZ set up the article structure and wrote the most parts of it, performed the literature analysis, contributed to the system analysis according to his research experience, developed the concept of the indicators and identified them, and was mainly responsible for the discussion and conclusions. SE coordinated the system analysis after F. Vester between the different research groups and contributed by lecturing the whole article and giving substantial input to its design. GS was the coordinator of the whole research project, assisted FZ in setting up the article structure, and gave input to all the parts of this article. All authors read and approved the final manuscript. 


\section{Ethics approval and consent to participate}

Not applicable

\section{Consent for publication}

Not applicable

\section{Competing interests}

The authors declare that they have no competing interests.

\section{Publisher's Note}

Springer Nature remains neutral with regard to jurisdictional claims in published maps and institutional affiliations.

\section{Author details}

'Austrian Energy Agency, Mariahilfer Strasse 136, 1150 Vienna, Austria. ${ }^{2}$ Institute of Spatial Planning, Environmental Planning and Land Rearrangement, University of Natural Resources and Life Sciences, Vienna, Peter-Jordan-Strasse 82, 1190 Vienna, Austria.

Received: 25 October 2018 Accepted: 12 May 2019

Published online: 25 June 2019

\section{References}

1. Statistik Austria (2016) Nutzenergieanalyse für Österreich 1993-2015, 2016 available on http://www.statistik.at/web_de/statistiken/energie_umwelt_ innovation_mobilitaet/energie_und_umwelt/energie/nutzenergieanalyse/ index.html (last access: 21.12.2017)

2. Dou Y, Togawa T, Dong L, Fujii M, Ohnisi S, Tanikawa H, Fujita T (2018) Innovative planning and evaluation system for district heating using waste heat considering spatial configuration: a case in Fukushima, Japan, Resources, Conservation and Recycling, volume 128, January 2018, Pages 406-416, doi: https://doi.org/10.1016/j.resconrec.2016.03.006

3. Werner $S$ (2017) International review of district heating and cooling. Energy 137(2017):617-631. https://doi.org/10.1016/j.energy.2017.04.045

4. Zarin Pass R, Wetter M, Piette MA (2017) A thermodynamic analysis of a novel bidirectional district heating and cooling network. https://doi.org/10. 1016/j.energy.2017.11.122

5. Schmidt D (2018) Low temperature district heating for future energy systems, energy procedia 149 (2018) 595-604, 16th International Symposium on District Heating and Cooling, DHC2018, 9-12 September 2018. Hamburg. https://doi.org/10.1016/j.egypro.2018.08.224

6. Vetterli N, Sulzer M, Menti U-P (2017) Energy monitoring of a low temperature heating and cooling district network, doi: https://doi.org/10. 1016/j.egypro.2017.07.289

7. Pol O, Schmidt R-R Development of district heating and cooling in the urban planning context, advanced district heating and cooling (DHC) systems. https://doi.org/10.1016/B978-1-78242-374-4.00015-X

8. Brange L, Englund J, Lauenburg P (2015) Prosumers in district heating networks - a Swedish case study. Appl Energy 2015. https://doi.org/10.1016/ j.apenergy.2015.12.020

9. Ichinose T, Kawahara H (2017) Regional feasibility study on district sewage heat supply in Tokyo with geographic information system. Sustainable Cities and Society, 2017 doi: https://doi.org/10.1016/j.scs.2017.04.002, last access: 17.01.2018

10. Kretschmer F, Weissenbacher N, Ertl T (2015) Integration of wastewater treatment plants into regional energy supply concepts. Sustain Sanit Pract 22:4-9

11. Neugebauer G, Kretschmer F, Kollmann R, Narodoslawsky M, Ertl T, Stoeglehner G (2015) Mapping thermal energy resource potentials from wastewater treatment plants. Sustainability (Switzerland) 7:12988-13010. https://doi.org/10.3390/su71012988

12. Neugebauer G, Stoeglehner G (2015) Realising energy potentials from wastewater by integrating spatial and energy planning. Sustain Sanit Pract 22:15-21

13. David A, Mathiesen BV, Averfalk H, Werner S, Lund H (2017) Heat roadmap Europe: large-scale electric heat pumps in district heating systems. Energies 10:578. https://doi.org/10.3390/en10040578

14. Erker S (2017). Räumliche Resilienz im Hinblick auf Energiekrisen. In Regenerative Räume. Leitbilder und Praktiken nachhaltiger Raumentwicklung. Hamburg, Vaduz, Wien: ÖKOM-Verlag
15. Erker S, Stangl R, Stoeglehner G (2017) Resilience in the light of energy crises - part l: a framework to conceptualise regional energy resilience. J Clean Prod. https://doi.org/10.1016/j.jclepro.2017.06.163

16. Statistik Austria (2017) Bevölkerung zu Jahres- und Quartalsanfang, available on http://www.statistik.at/web_de/statistiken/menschen_und_gesellschaft/ bevoelkerung/bevoelkerungsstand_und_veraenderung/bevoelkerung_zu_ jahres-_quartalsanfang/index.html, (last access: 21.12.2017)

17. Park S-Y, Lee K-S, Yoo S-H (2016) Economies of scale in the Korean district heating system: a variable cost function approach, doi: https://doi.org/10. 1016/j.enpol.2015.10.026

18. Persson U, Werner S (2011) Heat distribution and the future competitiveness of district heating, doi: https://doi.org/10.1016/j.apenergy. 2010.09.020

19. Kirkerud JG, Bolkesjø TF, Trømborg E (2017) Power-to-heat as a flexibility measure for integration of renewable energy, Energy (2017), doi: https://doi. org/10.1016/j.energy.2017.03.153

20. Frederiksen S, Werner S (2013) District heating and cooling. Studentlitteratur AB, ISBN-10: 914408533

21. Stoeglehner G, Neugebauer G, Erker S, Narodoslawsky M (2016) Integrated spatial and energy planning, supporting climate protection and the energy turn with means of spatial planning, Springer Briefs in Applied Sciences and Technology, ISBN 978-3-319-31868-4

22. Lund H, Werner S, Wiltshire R, Svendsen S, Thorsen, J-E, Hvelplund F, Mathiesen B-V (2014) 4th generation district heating (4GDH): integrating smart thermal grids into future sustainable energy systems, doi: https://doi. org/10.1016/j.energy.2014.02.089

23. Andric I, Gomes N, Pina A, Ferrao P, Fournier J, Lacarrigraveere B, Le Corre O (2016) Modeling the long-term effect of climate change on building heat demand: case study on a district level. Energy and Buildings. https://doi.org/ 10.1016/j.enbuild.2016.04.082

24. Kipping A, Trømborg E (2017) Modeling hourly consumption of electricity and district heat in non-residential buildings, Energy (2017), doi: https://doi. org/10.1016/j.energy.2017.01.108

25. Hast A, Rinne S, Syri S, Kiviluoma J $(2017,2017)$ The role of heat storages in facilitating the adaptation of district heating systems to large amount of variable renewable electricity. Energy. https://doi.org/10.1016/j.energy.2017. 05.113

26. Erb H-F, Vester F (1972) Unsere Städte sollen leben. Pro Umwelt Bilanz eines Ideenwettbewerbs. Deutsche Verlags-Anstalt, Stuttgart

27. Vester F (1997) Neuland des Denkens. DTV, München

28. Vester F (1976) Ballungsgebiete in der Krise. Vom Verstehen und Planen menschlicher Lebensräume. Deutscher Taschenbuchverlag, München

29. Vester F (2012) Die Kunst vernetzt zu denken: Ideen und Werkzeuge für einen neuen Umgang mit Komplexität Ein Bericht an den Club of Rome, 9th edn. dtv Verlagsgesellschaft, München

30. Stöglehner G, Narodoslawsky M, Steinmüller H, Steininger K, Weiss M, Mitter H, Neugebauer G, Weber G, Niemetz N, Kettl K-H, Eder M, Sandor N Pflüglmayer B, Markl B, Kollmann A, Friedl C, Lindorfer J, Luger M, Kulmer V (2011) PlanVision - Visionen für eine energieoptimierte Raumplanung. Klima- und Energiefonds, Wien

31. Bortz (2005) Statistik für Human- und Sozialwissenschaftler. Springer Medizin Verlag, Heidelberg

32. Belaid F, Bakaloglou S, Roubaud D (2018) Direct rebound effect of residential gas demand: empirical evidence from France, energy policy, vol 115, pp 23-31. https://doi.org/10.1016/j.enpol.2017.12.040

33. Stoeglehner G, Erker S, Neugebauer G (2014) Energieraumplanung. Materialienband, for Bundesministerium für Land- und Forstwirtschaft, Umwelt und Wasserwirtschaft. Österreichische Raumordnungskonferenz, Vienna

34. Wang M, Madden M, Liu X (2017) Exploring the relationship between urban forms and CO2 emissions in 104 Chinese cities. https://doi.org/10.1061/ (ASCE) UP. 1943-5444.0000400

35. Karathanassi V, lossifidis C, Rokos D (2000) A texture-based classification method for classifying built areas according to their density. https://doi.org/ 10.1080/014311600209751

36. Yu B, Liu H, Wu J, Hu Y, Zhang L (2010) Automated derivation of urban building density information using airborne LiDAR data and object-based method. https://doi.org/10.1016/j.landurbplan.2010.08.004

37. Gadd H, Werner S (2014) Achieving low return temperatures from district heating substations. Appl Energy 136:59-67. https://doi.org/10.1016/j. apenergy.2014.09.022 
38. OEROK (2010): Kleinräumige Bevölkerungsprognose für Österreich 2010-2030 mit Ausblick bis 2050, available on http://www.oerok.gv.at/ fileadmin/Bilder/2.Reiter-Raum_u._Region/2.Daten_und_Grundlagen/ Bevoelkerungsprognosen/Prognose_2010_Teil1/Endbericht_ Bevoelkerungsprognose_08-2010.pdf (last access: 18.01.2018)

39. United Nations, Poulation Division: World Urbanization Prospects 2018, https://population.un.org/wup/Download/ (last access: 01.10.2018)

40. Oberhuber A, Denk D (2014) Zahlen, Daten, Fakten zu Wohnungspolitik und Wohnungswirtschaft in Österreich, Forschungsgesellschaft für Wohnen, Bauen und Planen, available on: https://www.bmdw.gv.at/KulturellesErbe/ Wohnungspolitik/Documents/Zahlen\%20Daten\%20und\%20Fakten\%20\%20Endbericht.pdf. Accessed 22 May 2019.

41. Amann C, Berger T, Formayer H, Korjenic A, Pospischal B, Neururer C, Smutny R Impacts of climate change upon cooling and heating energy demand of office buildings in Vienna, Austria. Energy and Buildings 2014. https://doi.org/10.1016/j.enbuild.2014.03.084

42. Spandagos C, Ng T-L (2017) Equivalent full-load hours for assessing climate change impact on building cooling and heating energy consumption in large Asian cities. Appl Energy 189(2017). https://doi. org/10.1016/j.apenergy.2016.12.039

43. APCC (2014) Österreichischer Sachstandsbericht Klimawandel 2014 (AAR14). Austrian Panel on Climate Change (APCC). Verlag der Österreichischen Akademie der Wissenschaften, Wien, Österreich 1096 Seiten. ISBN 978-3-7001-7699-2

44. UBA - Umweltbundesamt (2016) Szenario Erneuerbare Energie 2030 und 2050. available on http://www.umweltbundesamt.at/fileadmin/site/ publikationen/REP0576.pdf (last access: 18.01.2018)

45. Liu M, Zhong Y, Tan J (2017) Impact of urban planning Indicator on spatial distribution of residential heating and cooling energy demand, 10th international symposium on heating, ventilation and air conditioning, ISHVAC2017, 19-22 October 2017, Jinan, China. Procedia Engineering 205: 959-966. https://doi.org/10.1016/j.proeng.2017.10.150

46. Erker S, Lichtenwoehrer P, Zach F, Stoeglehner G (2019) Interdisciplinary decision support model for grid-bound heat supply systems in urban areas. Energy sustainability and society 2019 9:11, Vienna https://doi.org/10.1186/ s13705-019-0193-4

47. Lichtenwoehrer P, Erker S, Zach F, Stoeglehner G (2019) Future compatibility of district heating in urban areas - a case study analysis in the context of integrated spatial and energy planning. Energy, sustainability and society 2019 9:12, Vienna https://doi.org/10.1186/s13705-019-0192-5

48. Li H, Nord N (2018) Transition to the 4th generation district heating possibilities, bottlenecks, and challenges, 16th International Symposium on District Heating and Cooling, DHC2018, 9-12 September 2018, Hamburg. https://doi.org/10.1016/j.egypro.2018.08.213

Ready to submit your research? Choose BMC and benefit from:

- fast, convenient online submission

- thorough peer review by experienced researchers in your field

- rapid publication on acceptance

- support for research data, including large and complex data types

- gold Open Access which fosters wider collaboration and increased citations

- maximum visibility for your research: over $100 \mathrm{M}$ website views per year

At BMC, research is always in progress.

Learn more biomedcentral.com/submissions 